\title{
CONTRIBUTION OF MONOAMINE OXIDASES TO VASCULAR OXIDATIVE STRESS IN PATIENTS WITH END-STAGE RENAL DISEASE REQUIRING HEMODIALYSIS
}

\begin{tabular}{|c|c|}
\hline Journal: & Canadian Journal of Physiology and Pharmacology \\
\hline Manuscript ID & cjpp-2017-0067.R1 \\
\hline Manuscript Type: & Article \\
\hline Date Submitted by the Author: & 31-May-2017 \\
\hline Complete List of Authors: & $\begin{array}{l}\text { Utu, Diana; University of Medicine and Pharmacy Timisoara, } \\
\text { Pathophysiology } \\
\text { Pantea, Stelian; University of Medicine and Pharmacy Timisoara, Surgery II } \\
\text { Duicu, Oana; "Victor Babes" University of Medicine and Pharmacy, } \\
\text { Department of Pathophysiology } \\
\text { Muntean, Danina; University of Medicine and Pharmacy Timisoara, } \\
\text { Pathophysiology; University of Medicine and Pharmacy Timisoara, Center } \\
\text { for Translational Research and Systems Medicine } \\
\text { Sturza, Adrian; University of Medicine and Pharmacy of Timisoara, } \\
\text { Pathophysiology; University of Medicine and Pharmacy Timisoara, Center } \\
\text { for Translational Research and Systems Medicine }\end{array}$ \\
\hline $\begin{array}{r}\text { Is the invited manuscript for } \\
\text { consideration in a Special } \\
\text { Issue?: }\end{array}$ & IACS European Section 2016 \\
\hline Keyword: & $\begin{array}{l}\text { arteriovenous fistula, monoamine oxidases, oxidative stress, endothelial } \\
\text { dysfunction }\end{array}$ \\
\hline
\end{tabular}

\section{SCHOLARONE" \\ Manuscripts}




\section{CONTRIBUTION OF MONOAMINE OXIDASES TO VASCULAR OXIDATIVE STRESS IN PATIENTS WITH END-STAGE RENAL DISEASE REQUIRING HEMODIALYSIS}

Diana Uțu ${ }^{1, \#}$, Stelian Pantea ${ }^{2, \#}$, Oana M. Duicu ${ }^{1,3}$, Danina M. Muntean ${ }^{1,3, *}$, Adrian Sturza ${ }^{1,3}$

${ }^{1}$ Department of Pathophysiology,

${ }^{2}$ Department of Surgery II,

${ }^{3}$ Center for Translational Research and Systems Medicine,

"Victor Babeș" University of Medicine and Pharmacy, Timișoara, Romania

${ }^{*}$ Corresponding author: Danina M. Muntean

Department of Pathophysiology,

"Victor Babeș" University of Medicine and Pharmacy of Timişoara

2, Eftimie Murgu Sq., 300041 Timisoara, RO

Tel: $+40-256-493085$

E-mail: daninamuntean@,umft.ro

${ }^{\#}$ These authors contributed equally to the work. 


\begin{abstract}
Arteriovenous fistula (AVF) is the 'lifeline' for patients with end-stage renal disease (ESRD) undergoing hemodialysis. AVF maturation failure is a poorly understood process, one of the contributors being endothelial dysfunction due to oxidative stress. Monoamine oxidases (MAOs) A and B were recently identified as novel sources of vascular oxidative stress. The aim of the present study was to assess the contribution of MAOs to the endothelial dysfunction in patients with ESDR with indication of hemodialysis. Fragments of brachial artery collaterals were harvested from ESRD patients during the surgical procedure aimed at creating the vascular access in the cubital fossa. The effect of increasing concentrations (10, $30,100 \mu \mathrm{mol} / \mathrm{L})$ of the irreversible MAO-A inhibitor, clorgyline and MAO-B inhibitor, selegyline, respectively on endothelial-dependent relaxation (EDR) in response to cumulative doses of acetylcholine was studied in isolated phenylephrine-preconstricted vascular rings. Hydrogen peroxide $\left(\mathrm{H}_{2} \mathrm{O}_{2}\right)$ production was assessed using ferrous oxidation xylenol orange assay. We showed that incubation of brachial rings with MAO inhibitors significantly improved EDR and attenuated $\mathrm{H}_{2} \mathrm{O}_{2}$ generation in patients with ESRD. MAO-related oxidative stress might contribute to the primary dysfunction/non-maturation of the AV fistula and MAO inhibitors could improve maturation and long-term patency of the vascular access in dialysis patients.
\end{abstract}

Keywords: arteriovenous fistula, monoamine oxidases, oxidative stress, endothelial dysfunction 


\section{Introduction}

Chronic kidney disease (CKD) is a characterized by an irreversible alteration of renal structure and function, lasting more than three months, and the association with a plethora of complications: metabolic, endocrine, cardiovascular, increased drug toxicity (Gadalean et al. 2016; Levin and Stevens 2014; Schiller et al. 2015). In its terminal stage (“end-stage renal disease", ESRD) long-term survival is possible only in conditions of chronic substitution of renal excretory function (dialysis or kidney transplantation). CKD is recognized as a major public health problem worldwide with an escalating prevalence in the last decade; globally there are over 2 million patients diagnosed with terminal CKD receiving dialysis replacement therapy (Hill et al. 2016; Mota et al. 2015).

The vast majority of ESRD patients rely on hemodialysis as long-term therapeutic approach. In this respect, the placement and maintenance of a functional vascular access is of paramount importance for patients' survival. According to the National Kidney FoundationKidney Disease Outcomes Quality Initiative and the European Best Practices Guidelines for vascular access, the dialysis access of choice is represented by an autologous arteriovenous fistula (AVF) also known as the Brescia-Cimino fistula or internal arteriovenous shunt (Kimball et al. 2011).

In short time, the most important complication of the AVF is primary failure as a consequence of the non-maturation process with high incidence in older, female patients or patients with previous vascular disorders (Pirozzi et al. 2016). The maturation process requires dilation of the arterial and venous vessel segments, in order to achieve a sufficient flow required for hemodialysis (minimum flow of $300 \mathrm{ml} / \mathrm{min}$ for at least 8 dialysis sessions According to the Dialysis Access Consortium) (Bashar et al. 2016). Failure in AV fistula maturation/patency is a poorly understood process that involves both hemodynamic and 
umoral factors. Among the latter group, a state of low-grade inflammation (Kuwahara et al. 2017; Wong et al. 2016) and long-term oxidative stress (with subsequent impairment of NO signaling) are both major pathomechanisms responsible for endothelial dysfunction in CKD (Geenen et al. 2016; Lee et al. 2016; Tsapenko et al. 2012) .

Monoamine oxidases (MAOs) are flavoenzymes with 2 isoforms, A and B, located at the outer mitochondrial membrane that have been recently recognized as relevant sources of cardiovascular oxidative stress in both experimental and clinical settings. Accordingly, we described the role of MAOs as mediators of endothelial dysfunction and the beneficial effect of MAO inhibition in murine diseased vessels (Sturza et al. 2013a; Sturza et al. 2013b), experimental diabetes mellitus (Sturza et al. 2015) and in patients with coronary artery disease subjected to revascularization procedures (Duicu et al. 2016; Duicu et al. 2015; Lighezan et al. 2016).

The present study was purported to assess the role of MAOs as contributors to the endothelial dysfunction in brachial artery collaterals harvested from ESRD patients with indication for hemodialysis.

\section{Material and methods}

Fragments of brachial artery collaterals were harvested from ESRD patients during the surgical procedure aimed at creating a brachiocephalic lateral-terminal fistula in the right cubital fossa.

The University Committee for Ethics Research approved the study protocol and the informed consent was obtained from all patients prior to surgery, according to the World Medical Association Declaration of Helsinki.

Characteristics of the patients included in the study are are presented in Table 1. 


\section{Preparation of Brachial Artery Collaterals and Isometric Tension Measurements}

After removal, brachial artery collaterals were placed in cold Hank's solution and immediately transferred to the laboratory. Organ bath experiments were performed in the presence of diclofenac $(10 \mu \mathrm{mol} / \mathrm{L})$ in order to eliminate the influence of prostaglandins on vascular reactivity according to a previously described protocol (Sturza et al. 2015; Sturza et al. 2013a). In brief, after an initial period of equilibration under a resting tension of $1.75 \mathrm{cN}$ (with the buffer replacement every $20 \mathrm{~min}$ ), rings were contracted twice with $\mathrm{KCl}$ to confirm the viability of the vascular smooth muscle. The endothelium-dependent relaxation (EDR) of preconstricted vascular rings to increasing concentrations of acetylcholine (ACh) was recorded. The concentration of phenylephrine (Phe) used for preconstriction, was adjusted to obtain an identical preconstriction level of $80 \%$ of the contraction elicited by $\mathrm{KCl}(80$ $\mathrm{mmol} / \mathrm{L})$.

EDR to cumulative Ach concentrations was recorded in the presence vs. absence of two irreversible MAO inhibitors (MAOI) applied in increasing concentrations $(10,30,100$ $\mu \mathrm{mol} / \mathrm{L}$ ), clorgyline - the inhibitor of MAO-A and selegiline - the inhibitor of MAO-B, respectively (incubation time, $30 \mathrm{~min}$ ). Nitric oxide (NO) bioavailability was estimated from the constrictor response to the eNOS inhibitor N-nitro-L-arginine (L-NAME, $10 \mu \mathrm{mol} / \mathrm{L}$ ) in human brachial artery collaterals rings preconstricted to $10 \%$ of the maximal $\mathrm{KCl}$ constriction using phenylephrine. In separate experiments, vascular samples were subjected to endothelium denudation by a short treatment with CHAPS $(5 \mathrm{mg} / \mathrm{mL}$ dissolved in glucose solution $50 \mathrm{~g} / \mathrm{L}$, exposure for 60 seconds).

\section{Reactive Oxygen Species (ROS) Measurement}

Hydrogen peroxide production was assessed in human brachial artery collaterals in the presence $v s$. absence of the MAOI (30 min preincubation with clorgyline and selegiline, 10 
$\mu \mathrm{mol} / \mathrm{L}$ ) by means of Ferrous iron xylenol orange OXidation (FOX) assay using the PeroxiDetect Kit (Sigma Aldrich) as previously described (Danila et al. 2017; Duicu et al. 2016; Sturza et al. 2015; Sturza et al. 2013a). The principle of the assay is that peroxides oxidize $\mathrm{Fe}^{2+}$ to $\mathrm{Fe}^{3+}$ ions at acidic $\mathrm{pH}$. The $\mathrm{Fe}^{3+}$ ion will form a colored adduct with xylenol orange, which is observed at $560 \mathrm{~nm}$.

\section{Statistics}

Data are presented as mean+SEM and analyzed using one-way ANOVA or student $t$ test when appropriate. Data analysis of the dose-effect response curves was performed using the ANOVA F-test (comparisons of bottom and top values, EC50 and the Hill slope). Values of $p<0.05$ were considered statistically significant.

\section{Results}

\section{Ex Vivo Inhibition of MAOs Reduced Contractility And Improved Relaxation Of Brachial Artery Collaterals From ESRD Patients}

MAOs have emerged in the past decades as important mediators of oxidative stress-related endothelial dysfunction both in animal models and cardiac patients. In the present study we assessed the effects of in vitro MAO inhibition on endothelial function in human brachial artery collaterals from ESRD patients, a pathological condition unequivocally associated with increased oxidative stress. As revealed by organ bath studies, in the presence of an intact endothelium, we found a significant rightward shift of the concentration-response curve to Phe in arteries treated with MAO inhibitors (regardless of the dose applied) as compared to the non-treated vessels (Fig. 1A, 2A). Subsequently, we measured the endothelium-dependent relaxation in response to cumulative doses of $\mathrm{ACh}$ in the presence vs. the absence of each 
MAOI, clorgyline and selegiline $(10,30,100 \mu \mathrm{mol} / \mathrm{L})$. Similarly, both drugs inhibitors significantly improved the relaxation response to Ach (Fig. 1B, 2B). Of note, we tested several MAOI concentrations - from 1 to $200 \mu \mathrm{mol} / \mathrm{L}$ (data not shown) but we obtained effects on vascular reactivity and ROS production in a rather narrow range, i.e. from 10 to 100 $\mu \mathrm{mol} / \mathrm{L}$.

The Vascular Effects After MAO Inhibition Are A Consequence Of The Increase In Nitric Oxide Availability

To elucidate whether the vascular effects after MAO inhibition are the consequence of the improvement in nitric oxide availability, in vascular preparations were incubated with either clorgyline or selegiline we measured the vascular contractility after the

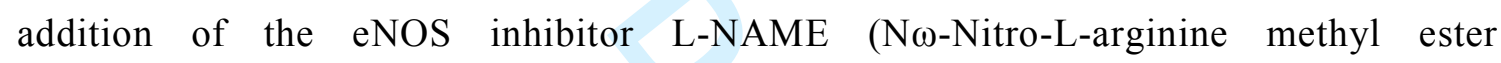
hydrochloride, $10 \mu \mathrm{M} / \mathrm{L}$ ). Since the endothelial nitric oxide (NO) generation was decreased, a subsequent increase in the vascular smooth muscle contractility was recorded in the non-treated vascular samples. At variance, in all vascular preparations incubated ex vivo with MAOI (regardless the dose), contractility in the presence of eNOS inhibitor was significantly decreased (Fig. 1C, 2C). These observations indirectly suggest that in the presence of MAOI, the improvement in endothelial-dependent relaxation of brachial artery collaterals from ESRD patients (Fig. 1B, 2B) was due, at least partially, to an increase in NO bioavailability.

\section{MAO Inhibitors Reduced The Vascular $\mathrm{H}_{2} \mathrm{O}_{2}$ Production In Brachial Artery Collaterals from ESRD patients}

While CKD is a condition that has been systematically associated with oxidative stress the sources of ROS are elusive. In the present study we also investigated the role of MAOs as 
sources of oxidative stress in patients with ESRD. In order to elucidate whether the restoration of vascular reactivity due to MAO inhibition might be related to the mitigation in ROS production we performed measurements of hydrogen peroxide by FOX assay. Incubation for 30 minutes with MAOI significantly reduced the amount of $\mathrm{H}_{2} \mathrm{O}_{2}$, suggesting that indeed, the reduction of oxidative stress contributes to the beneficial vascular effects of MAOI (Fig. 4A).

\section{Endothelial Denudation Abolished The Effects Of MAOI}

We further questioned whether a functional endothelium is mandatory for the effects of MAOI. Indeed, endothelial denudation with CHAPS completely abolished the effects of the pharmacological inhibitors on vascular reactivity (Fig. 3A-B) and $\mathrm{H}_{2} \mathrm{O}_{2}$ production (Fig. 4B), respectively. These results strongly suggest that the presence of intact endothelial cells is mandatory for the favorable effects of MAOI on diseased vessels.

\section{Discussions}

In this study, we investigated the role of MAO in ROS generation and endothelial dysfunction in brachial artery collaterals harvested from patients with ESRD subjected to the surgical creation of the AV fistula. We showed here for the first time that MAOs' inhibition reduced the level of oxidative stress and improved vascular reactivity by decreasing contractility and increasing relaxation in the diseased vessels. The second major finding is that the presence of an intact endothelial layer is mandatory for the beneficial effects of MAOI. This latter observation is in line with our results in vessels harvested from patients with coronary heart disease, another condition associated with low-grade inflammation and various degrees of oxidative stress. Indeed, in this earlier study, incubation of the denuded mammary arteries with either MAOI, did not result in alleviation of the endothelial dysfunction (Lighezan et al. 2016). This observation might also imply that a normal 
endothelial cell-to-cell adhesion and communication (Dlugosova et al. 2009; Frimmel et al. 2014) are equally required for the appropriate fistula maturation, a hypothesis that deserve further investigation.

Albeit the mechanism underlying the MAOI-related improvement in the endothelialdependent relaxation has not be directly investigated (an important limitation of the present study), our previous experimental data are pointing to a critical role for nitric oxide (NO). Indeed, in human umbilical vein endothelial cells, MAO-A and B inhibition increased the level of cyclic guanosin monophosphate and thus, the NO bioavailability (Sturza et al. 2013a).

Collectively, our data are suggestive for the contribution of MAO-related oxidative stress to the vascular impairment in patients with advanced CKD requiring hemodialysis that might further impact on fistula maturation and/or survival. Factors responsible for the defective maturation and/or malfunctioning of the vascular access in patients with CKD are incompletely elucidated. Therefore, understanding the complex pathophysiology that underlies endothelial dysfunction in the setting of renal failure is crucial for a long-term viability of the vascular access. In particular, the hemodynamic abnormalities elicited by the surgical anastomosis of a high pressure artery to a low pressure vein have been systematically studied (Hammes 2015); indeed, neointimal hyperplasia and subsequent venous stenosis have been reported to be the major culprits responsible for the vascular access failure (Stolic 2013). However, the trigger event that initiate the intimal hyperplasia remains elusive (Cunnane et al. 2017). Clearly, chronic accumulation of uremic toxins is primarily responsible for increased arterial stiffness, endothelial hyperplasia and calcification in patients with renal failure (Nemcsik et al. 2012). Moreover, hemodialysis is a treatment that contributes per se to the oxidative stress (and reduced NO formation) through the shear stress of the venous endothelial cells (Hammes 2015). 
Several sources of oxidative stress have been systematically reported to contribute to ROS generation in CKD (Kashihara et al. 2010), such as NAD(P)H oxidases (Brandes et al. 2014), uncoupled nitric oxide synthases ( $\mathrm{Li}$ et al. 2014), xanthine oxidase (Kim et al. 2017), the respiratory chain at the inner mitochondrial membrane (Bhatti et al. 2016), and p66Shc (Zanetti et al. 2011).

In the recent years, MAO-A and B have been reported as novel sources of oxidative stress in the cardiovascular system due to constant generation of hydrogen peroxide $\left(\mathrm{H}_{2} \mathrm{O}_{2}\right)$ as by-product of the oxidative deamination of biogenic amines and neurotransmitters (Kaludercic et al. 2014; Sorato et al. 2014). While MAO-B, the predominant isoform in the brain, has been extensively studied for almost one century, MAO-A present in brain and in other tissues, including heart and vasculature (Di Lisa et al. 2009) has been only more recently (re)discovered. Interestingly, in 2005, Xu described a new isoform (MAO-C) or renalase, mainly released by the kidneys ( $\mathrm{Xu}$ et al. 2005). In CKD renalase is significantly decreased which is an important cause of reduced catecholamine clearance with sympathetic over-activation (Wang et al. 2015) and a well-documented increase in cardiovascular risk and mortality (Quelhas-Santos and Pestana 2014). Of note, in CKD patients norepinephrine clearance is reduced by $20 \%$ in mild renal impairment and by up to $40 \%$ in hemodialysis patients (Zbroch et al. 2012). Accordingly, it is tempting to speculate that the catecholamine clearance will be increasingly performed via the A and B MAO isoforms with subsequent higher $\mathrm{H}_{2} \mathrm{O}_{2}$ generation. In our study incubation with either MAOI significantly reduced the amount of $\mathrm{H}_{2} \mathrm{O}_{2}$ in the vascular samples from ESRD patients. These results are in line with our previous studies in human internal mammary arteries harvested from coronary patients, where MAOI significantly reduced the amount of $\mathrm{H}_{2} \mathrm{O}_{2}$ (Duicu et al. 2016; Lighezan et al. 2016) (Sturza et al. 2013a). In this regard, in the present study we noticed the reduction of the 
contractility to L-NAME after incubation of the vascular samples with MAOI, as functional marker of a significant improvement in NO bioavailability.

Currently there are no pharmacological approaches for preventing the vascular access failure in patients on hemodialysis. In two recent retrospectives studies, ACE inhibitors, angiotensin receptors blockers and calcium channel blockers (Chen et al. 2016), as well as statins (Chang et al. 2016) were reported to be strongly associated with the increase in the long-term AVF patency. Nowadays, several reversible MAOI are available in clinical practice for the treatment of neurodegenerative disorders and depression which renders them candidates for drug repurposing in pathologies associated with increased oxidative stress and cardiovascular mortality. Of note, these drugs are devoid of the irreversible MAOI sideeffects (in particular, the feared 'cheese effect') and might be used in patients with ESRD requiring hemodialysis where anxiety and depression are already present from the beginning of the therapy (Rebollo Rubio et al. 2017).

We have to mention that patients included in this pilot study had a severe anemia $(\mathrm{Hb}$ and Ht values in Table 1) prior to the establishment of the vascular access that clearly need to be corrected in order to decrease the cardiovascular risk. In these patients, renal anemia is mainly due to a decreased erythropoietin production but other factors are involved such as iron deficiency, inhibition of erythropoiesis and increased hemolysis due to uremic toxins and also, deficiency in B12 and folic acid (Hayashi et al. 2015). Clearly, the subsequent tissue hypoxia elicits compensatory changes that in long term may become maladaptive and further contribute to the endothelial dysfunction.

Optimizing the vascular access remains an unmet need in day-to-day practice of the dialysis centers view the high rate of mortality (up to $25 \%$ of patients) due to AVF failure or its complications (Schild 2010). We report here that MAOs at the outer mitochondrial membrane are novel sources of vascular oxidative stress in patients with end-stage renal 
disease. It is tempting to speculate that preoperative MAO inhibition, prior to the establishment of the vascular access might contribute to the maturation and patency of the AVF, the 'life line` for hemodialysis patients.

\section{Conclusions}

With the present study, we have established that in vitro inhibition of MAOs significantly improved endothelium-dependent relaxation and reduced ROS level in human brachial artery collaterals isolated from patients with end-stage renal disease with indication of hemodialysis. Although much remains to be done in adequately assessing their long-term clinical efficacy, these preliminary results suggest that MAO inhibitors might be useful in the management of the vascular access in hemodialysis patients.

\section{Conflicts of interest}

The authors confirm that this article content has no conflicts of interest.

\section{References}

Bashar, K., Conlon, P.J., Kheirelseid, E.A., Aherne, T., Walsh, S.R., and Leahy, A. 2016. Arteriovenous fistula in dialysis patients: Factors implicated in early and late AVF maturation failure. The surgeon : journal of the Royal Colleges of Surgeons of Edinburgh and Ireland 14(5): 294-300. doi: 10.1016/j.surge.2016.02.001.

Bhatti, J.S., Bhatti, G.K., and Reddy, P.H. 2016. Mitochondrial dysfunction and oxidative stress in metabolic disorders - A step towards mitochondria based therapeutic strategies. Biochimica et biophysica acta. doi: 10.1016/j.bbadis.2016.11.010. 
Brandes, R.P., Weissmann, N., and Schroder, K. 2014. Nox family NADPH oxidases: Molecular mechanisms of activation. Free radical biology \& medicine 76: 208-226. doi: 10.1016/j.freeradbiomed.2014.07.046.

Chang, H.H., Chang, Y.K., Lu, C.W., Huang, C.T., Chien, C.T., Hung, K.Y., Huang, K.C., and Hsu, C.C. 2016. Statins Improve Long Term Patency of Arteriovenous Fistula for Hemodialysis. Scientific reports 6: 22197. doi: 10.1038/srep22197.

Chen, F.A., Chien, C.C., Chen, Y.W., Wu, Y.T., and Lin, C.C. 2016. Angiotensin Converting-Enzyme Inhibitors, Angiotensin Receptor Blockers, and Calcium Channel Blockers Are Associated with Prolonged Vascular Access Patency in Uremic Patients Undergoing Hemodialysis. PloS one 11(11): e0166362. doi: 10.1371/journal.pone.0166362.

Cunnane, C.V., Cunnane, E.M., and Walsh, M.T. 2017. A Review of the Hemodynamic Factors Believed to Contribute to Vascular Access Dysfunction. Cardiovascular engineering and technology. doi: 10.1007/s13239-017-0307-0.

Danila, M.D., Privistirescu, A., Duicu, O.M., Ratiu, C.D., Angoulvant, D., Muntean, D.M., and Sturza, A. 2017. The effect of purinergic signaling via the P2Y11 receptor on vascular function in a rat model of acute inflammation. Molecular and cellular biochemistry. doi: 10.1007/s11010-017-2973-5.

Di Lisa, F., Kaludercic, N., Carpi, A., Menabo, R., and Giorgio, M. 2009. Mitochondria and vascular pathology. Pharmacological reports : PR 61(1): 123-130.

Dlugosova, K., Okruhlicova, L., Mitasikova, M., Sotnikova, R., Bernatova, I., Weismann, P., Slezak, J., and Tribulova, N. 2009. Modulation of connexin-43 by omega-3 fatty acids in the aorta of old spontaneously hypertensive rats. Journal of physiology and pharmacology : an official journal of the Polish Physiological Society 60(3): 63-69.

Duicu, O.M., Lighezan, R., Sturza, A., Balica, R., Vaduva, A., Feier, H., Gaspar, M., Ionac, A., Noveanu, L., Borza, C., Muntean, D.M., and Mornos, C. 2016. Assessment of 
Mitochondrial Dysfunction and Monoamine Oxidase Contribution to Oxidative Stress in Human Diabetic Hearts. Oxid Med Cell Longev 2016: 8470394. doi: 10.1155/2016/8470394.

Duicu, O.M., Lighezan, R., Sturza, A., Ceausu, R.A., Borza, C., and Vaduva, A. 2015. Monoamine Oxidases as Potential Contributors to Oxidative Stress in Diabetes: Time for a Study in Patients Undergoing Heart Surgery. 2015: 515437. doi: 10.1155/2015/515437.

Frimmel, K., Vlkovicova, J., Sotnikova, R., Navarova, J., Bernatova, I., and Okruhlicova, L. 2014. The effect of omega-3 fatty acids on expression of connexin-40 in Wistar rat aorta after lipopolysaccharide administration. Journal of physiology and pharmacology : an official journal of the Polish Physiological Society 65(1): 83-94.

Gadalean, F., Lighezan, D., Stoian, D., Schiller, O., Timar, R., Timar, B., Bob, F., Donciu, M.D., Munteanu, M., Mihaescu, A., Covic, A., and Schiller, A. 2016. The Survival of Roma Minority Patients on Chronic Hemodialysis Therapy - A Romanian Multicenter Survey. PloS one 11(5): e0155271. doi: 10.1371/journal.pone.0155271.

Geenen, I.L., Kolk, F.F., Molin, D.G., Wagenaar, A., Compeer, M.G., Tordoir, J.H., Schurink, G.W., De Mey, J.G., and Post, M.J. 2016. Nitric Oxide Resistance Reduces Arteriovenous Fistula Maturation in Chronic Kidney Disease in Rats. PloS one 11(1): e0146212. doi: 10.1371/journal.pone.0146212.

Hammes, M. 2015. Hemodynamic and biologic determinates of arteriovenous fistula outcomes in renal failure patients. BioMed research international 2015: 171674. doi: $10.1155 / 2015 / 171674$.

Hayashi, T., Joki, N., Tanaka, Y., and Hase, H. 2015. Anaemia and early phase cardiovascular events on haemodialysis. Nephrology (Carlton, Vic.) 20 Suppl 4: 1-6. doi: 10.1111/nep.12642. 
Hill, N.R., Fatoba, S.T., Oke, J.L., Hirst, J.A., O'Callaghan, C.A., Lasserson, D.S., and Hobbs, F.D. 2016. Global Prevalence of Chronic Kidney Disease - A Systematic Review and MetaAnalysis. PloS one 11(7): e0158765. doi: 10.1371/journal.pone.0158765.

Kaludercic, N., Mialet-Perez, J., Paolocci, N., Parini, A., and Di Lisa, F. 2014. Monoamine oxidases as sources of oxidants in the heart. Journal of molecular and cellular cardiology 73 : 34-42. doi: 10.1016/j.yjmcc.2013.12.032.

Kashihara, N., Haruna, Y., Kondeti, V.K., and Kanwar, Y.S. 2010. Oxidative stress in diabetic nephropathy. Current medicinal chemistry 17(34): 4256-4269.

Kim, Y.J., Ryu, H.M., Choi, J.Y., Cho, J.H., Kim, C.D., Park, S.H., and Kim, Y.L. 2017. Hypoxanthine causes endothelial dysfunction through oxidative stress-induced apoptosis. Biochemical and biophysical research communications 482(4): 821-827. doi: 10.1016/j.bbrc.2016.11.119.

Kimball, T.A., Barz, K., Dimond, K.R., Edwards, J.M., and Nehler, M.R. 2011. Efficiency of the kidney disease outcomes quality initiative guidelines for preemptive vascular access in an academic setting. Journal of vascular surgery 54(3): 760-765; discussion 765-766. doi: 10.1016/j.jvs.2011.03.006.

Kuwahara, G., Hashimoto, T., Tsuneki, M., Yamamoto, K., Assi, R., Foster, T.R., Hanisch, J.J., Bai, H., Hu, H., Protack, C.D., Hall, M.R., Schardt, J.S., Jay, S.M., Madri, J.A., Kodama, S., and Dardik, A. 2017. CD44 Promotes Inflammation and Extracellular Matrix Production During Arteriovenous Fistula Maturation. Arteriosclerosis, thrombosis, and vascular biology. doi: 10.1161/atvbaha.117.309385.

Lee, K.H., Tsai, W.J., Chen, Y.W., Yang, W.C., Lee, C.Y., Ou, S.M., Chen, Y.T., Chien, C.C., Lee, P.C., Chung, M.Y., and Lin, C.C. 2016. Genotype polymorphisms of genes regulating nitric oxide synthesis determine long-term arteriovenous fistula patency in male hemodialysis patients. Renal failure 38(2): 228-237. doi: 10.3109/0886022x.2015.1120096. 
Levin, A., and Stevens, P.E. 2014. Summary of KDIGO 2012 CKD Guideline: behind the scenes, need for guidance, and a framework for moving forward. Kidney international $\mathbf{8 5}(1)$ : 49-61. doi: 10.1038/ki.2013.444.

Li, H., Horke, S., and Forstermann, U. 2014. Vascular oxidative stress, nitric oxide and atherosclerosis. Atherosclerosis 237(1): 208-219. doi: 10.1016/j.atherosclerosis.2014.09.001. Lighezan, R., Sturza, A., Duicu, O.M., Ceausu, R.A., Vaduva, A., Gaspar, M., Feier, H., Vaida, M., Ivan, V., Lighezan, D., Muntean, D.M., and Mornos, C. 2016. Monoamine oxidase inhibition improves vascular function in mammary arteries from nondiabetic and diabetic patients with coronary heart disease. Can J Physiol Pharmacol 94(10): 1040-1047. doi: 10.1139/cjpp-2015-0580.

Mota, E., Popa, S.G., Mota, M., Mitrea, A., Penescu, M., Tuta, L., Serafinceanu, C., Hancu, N., Garneata, L., Verzan, C., Lichiardopol, R., Zetu, C., Capusa, C., Vladutiu, D., Guja, C., Catrinoiu, D., Bala, C., Roman, G., Radulian, G., Timar, R., and Mihai, B. 2015. Prevalence of chronic kidney disease and its association with cardio-metabolic risk factors in the adult Romanian population: the PREDATORR study. International urology and nephrology 47(11): 1831-1838. doi: 10.1007/s11255-015-1109-7.

Nemcsik, J., Kiss, I., and Tisler, A. 2012. Arterial stiffness, vascular calcification and bone metabolism in chronic kidney disease. World journal of nephrology 1(1): 25-34. doi: 10.5527/wjn.v1.i1.25.

Pirozzi, N., Medina, J.G., and Mene, P. 2016. Impaired maturation of distal radio-cephalic fistula for haemodialysis: a review of treatment options. Journal of nephrology. doi: $10.1007 / \mathrm{s} 40620-016-0332-3$.

Quelhas-Santos, J., and Pestana, M. 2014. Plasma renalase in chronic kidney disease: differences and similarities between humans and rats. Current hypertension reviews 10(3): 166-170. 
Rebollo Rubio, A., Morales Asencio, J.M., and Eugenia Pons Raventos, M. 2017. Depression, anxiety and health-related quality of life amongst patients who are starting dialysis treatment. Journal of renal care 43(2): 73-82. doi: 10.1111/jorc.12195.

Schild, A.F. 2010. Maintaining vascular access: the management of hemodialysis arteriovenous grafts. The journal of vascular access 11(2): 92-99.

Schiller, A., Gadalean, F., Schiller, O., Timar, R., Bob, F., Munteanu, M., Stoian, D., Mihaescu, A., and Timar, B. 2015. Vitamin D deficiency--prognostic marker or mortality risk factor in end stage renal disease patients with diabetes mellitus treated with hemodialysis--a prospective multicenter study. PloS one 10(5): e0126586. doi: 10.1371/journal.pone.0126586. Sorato, E., Menazza, S., Zulian, A., Sabatelli, P., Gualandi, F., Merlini, L., Bonaldo, P., Canton, M., Bernardi, P., and Di Lisa, F. 2014. Monoamine oxidase inhibition prevents mitochondrial dysfunction and apoptosis in myoblasts from patients with collagen VI myopathies. Free radical biology \& medicine 75: 40-47. doi: 10.1016/j.freeradbiomed.2014.07.006.

Stolic, R. 2013. Most important chronic complications of arteriovenous fistulas for hemodialysis. Medical principles and practice : international journal of the Kuwait University, Health Science Centre 22(3): 220-228. doi: 10.1159/000343669.

Sturza, A., Duicu, O.M., Vaduva, A., Danila, M.D., Noveanu, L., Varro, A., and Muntean, D.M. 2015. Monoamine oxidases are novel sources of cardiovascular oxidative stress in experimental diabetes. Can J Physiol Pharmacol 93(7): 555-561. doi: 10.1139/cjpp-20140544.

Sturza, A., Leisegang, M.S., Babelova, A., Schroder, K., Benkhoff, S., Loot, A.E., Fleming, I., Schulz, R., Muntean, D.M., and Brandes, R.P. 2013a. Monoamine oxidases are mediators of endothelial dysfunction in the mouse aorta. Hypertension (Dallas, Tex. : 1979) 62(1): 140146. doi: 10.1161/hypertensionaha.113.01314. 
Sturza, A., Mirica, S.N., Duicu, O., Gheorgheosu, D., Noveanu, L., Fira-Mladinescu, O., and Muntean, D.M. 2013b. Monoamine oxidase--a inhibition reverses endothelial dysfunction in hypertensive rat aortic rings. Revista medico-chirurgicala a Societatii de Medici si Naturalisti din Iasi 117(1): 165-171. doi: 10.1139/cjpp-2014-0544.

Tsapenko, M.V., d'Uscio, L.V., Grande, J.P., Croatt, A.J., Hernandez, M.C., Ackerman, A.W., Katusic, Z.S., and Nath, K.A. 2012. Increased production of superoxide anion contributes to dysfunction of the arteriovenous fistula. American journal of physiology. Renal physiology 303(12): F1601-1607. doi: 10.1152/ajprenal.00449.2012.

Wang, F., Li, J., Xing, T., Xie, Y., and Wang, N. 2015. Serum renalase is related to catecholamine levels and renal function. Clinical and experimental nephrology 19(1): 92-98. doi: 10.1007/s10157-014-0951-8.

Wong, C., Bezhaeva, T., Rothuizen, T.C., Metselaar, J.M., de Vries, M.R., Verbeek, F.P., Vahrmeijer, A.L., Wezel, A., van Zonneveld, A.J., Rabelink, T.J., Quax, P.H., and Rotmans, J.I. 2016. Liposomal prednisolone inhibits vascular inflammation and enhances venous outward remodeling in a murine arteriovenous fistula model. Scientific reports 6: 30439 . doi: $10.1038 /$ srep30439.

Xu, J., Li, G., Wang, P., Velazquez, H., Yao, X., Li, Y., Wu, Y., Peixoto, A., Crowley, S., and Desir, G.V. 2005. Renalase is a novel, soluble monoamine oxidase that regulates cardiac function and blood pressure. The Journal of clinical investigation 115(5): 1275-1280. doi: $10.1172 / \mathrm{jci} 24066$.

Zanetti, M., Barazzoni, R., Gortan Cappellari, G., Burekovic, I., Bosutti, A., Stocca, A., Bianco, F., Ianche, M., Panzetta, G., and Guarnieri, G. 2011. Hemodialysis induces p66(shc) gene expression in nondiabetic humans: correlations with oxidative stress and systemic inflammation. Journal of renal nutrition : the official journal of the Council on Renal Nutrition of the National Kidney Foundation 21(5): 401-409. doi: 10.1053/j.jrn.2010.12.006. 
Zbroch, E., Malyszko, J., Malyszko, J., Koc-Zorawska, E., and Mysliwiec, M. 2012. Renalase in peritoneal dialysis patients is not related to blood pressure, but to dialysis vintage. Peritoneal dialysis international : journal of the International Society for Peritoneal Dialysis 32(3): 348-351. doi: 10.3747/pdi.2011.00118. 
Table 1. Characteristics of the study group.

\begin{tabular}{|c|c|}
\hline \multicolumn{2}{|c|}{ Demographics of ESRD patients $(\boldsymbol{n}=\mathbf{3 0}):$ Age $(52 \pm 9)$; Gender $(13 \hat{\jmath}, 17 q$} \\
\hline Laboratory data & Values \\
\hline Creatinine (mg/dl) & $5.9 \pm 3.1$ \\
\hline eGFR $\left(\mathrm{ml} / \mathrm{min} / 1.73 \mathrm{~m}^{2}\right)$ & $6 \pm 2$ \\
\hline Urea (mg/dl) & $170 \pm 56$ \\
\hline Potasium (mmol/l) & $5.2 \pm 1.4$ \\
\hline Sodium $(\mathrm{mmol} / \mathrm{l})$ & $128 \pm 6$ \\
\hline Blood glucose (mg/dl) & $105 \pm 10$ \\
\hline Fibrinogen (mg/dl) & $460 \pm 25$ \\
\hline Hemoglobin $\left(\delta^{\Uparrow}\right)(\mathrm{g} / \mathrm{dl})$ & $9.2 \pm 1.4$ \\
\hline Hemoglobin (q) (g/dl) & $8.3 \pm 1.1$ \\
\hline Hematocrit $\left({ }^{\lambda}\right)(\%)$ & $27.8 \pm 7.5$ \\
\hline Hematocrit ( $(+)(\%)$ & $24.2 \pm 8.2$ \\
\hline Leukocytes $\left(\times 10^{3} / \mu 1\right)$ & $10.1 \pm 2.3$ \\
\hline Platelets $\left(\mathrm{x} 10^{3} / \mu \mathrm{l}\right)$ & $120 \pm 23$ \\
\hline Cholesterol (mg/dl) & $263 \pm 29$ \\
\hline Triglycerides (mg/dl) & $231 \pm 25$ \\
\hline $\operatorname{ESR}(\mathrm{mm} / \mathrm{h})$ & $30 \pm 15$ \\
\hline
\end{tabular}

eGFR = estimated Glomerular Filtration Rate, ESR = Erythrocyte Sedimentation Rate Data are means \pm S.E.M. 
Figure 1. The effect of MAO-A inhibitor Clorgyline on vasomotor function in brachial artery collaterals with intact endothelium: (A) Phenylephrine induced contractions, (B) Acetylcholine-induced relaxation and (C) contraction to L-NAME $(10 \mu \mathrm{mol} / \mathrm{L})$ in brachial artery collaterals segments isolated from ESRD patients with indication of hemodialysis in the presence vs. absence of MAO-A inhibitor clorgyline (ESRD+Clorg, $10 \mu \mathrm{mol} / \mathrm{L}, 30 \mu \mathrm{mol} / \mathrm{L}$, $100 \mu \mathrm{mol} / \mathrm{L}) . \mathrm{n}=30,{ }^{*}, \AA \& p<0.05$ ESRD with $v s$. without the named inhibitor.

Figure 2. The effect of MAO-B inhibitor Selegiline on vasomotor function in brachial artery collaterals with intact endothelium: (A) Phenylephrine induced contractions, (B) Acetylcholine-induced relaxation and (C) contraction to L-NAME $(10 \mu \mathrm{mol} / \mathrm{L})$ in brachial artery collaterals segments isolated from ESRD patients with indication of hemodialysis in the presence vs. absence of MAO-B inhibitor selegiline (ESRD+Seleg, $10 \mu \mathrm{mol} / \mathrm{L}, 30 \mu \mathrm{mol} / \mathrm{L}$, $100 \mu \mathrm{mol} / \mathrm{L}) . \mathrm{n}=30,{ }^{*}, \AA \&<0.05$ ESRD with $v s$. without the named inhibitor.

Figure 3. The effect of MAO inhibitors on vasomotor function in brachial artery collaterals with denuded endothelium: Phenylephrine induced contractions in brachial artery collaterals segments with denuded endothelium, isolated from ESRD patients with indication of hemodialysis in the presence vs. absence of (A) MAO-A inhibitor clorgyline (ESRD+Clorg, $10 \mu \mathrm{mol} / \mathrm{L}, 30 \mu \mathrm{mol} / \mathrm{L}, 100 \mu \mathrm{mol} / \mathrm{L}$ ) and (B) MAO-B inhibitor selegiline (ESRD+Seleg, $10 \mu \mathrm{mol} / \mathrm{L}, 30 \mu \mathrm{mol} / \mathrm{L}, 100 \mu \mathrm{mol} / \mathrm{L}) . \mathrm{n}=30, *, \#, \&<0.05$ ESRD with $v s$. without the named inhibitor.

Figure 4. The effect of MAO inhibitors on ROS production in brachial artery collaterals. (A) FOX Assay for $\mathrm{H}_{2} \mathrm{O}_{2}$ measurements in brachial artery collaterals segments with endothelium and (B) denuded endothelium, isolated from ESRD patients with indication 
of hemodialysis in the presence vs. absence of MAO-A inhibitor clorgyline (ESRD+Clorg, 10 $\mu \mathrm{mol} / \mathrm{L}, 30 \mu \mathrm{mol} / \mathrm{L}, 100 \mu \mathrm{mol} / \mathrm{L}$ ) and MAO-B inhibitor selegiline (ESRD+Seleg, $10 \mu \mathrm{mol} / \mathrm{L}$, $30 \mu \mathrm{mol} / \mathrm{L}, 100 \mu \mathrm{mol} / \mathrm{L}) . \mathrm{n}=30,{ }^{* 1-6} p<0.05 \mathrm{ESRD}$ with $v s$. without the named inhibitor. 


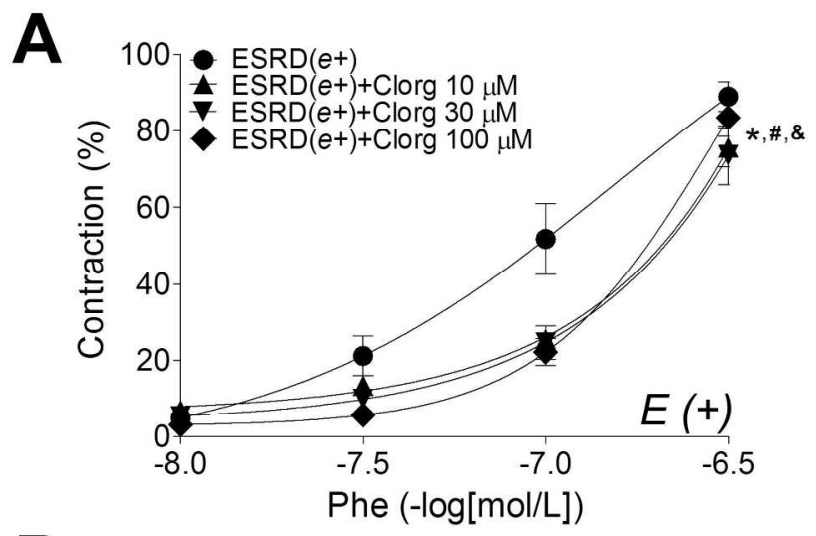

B
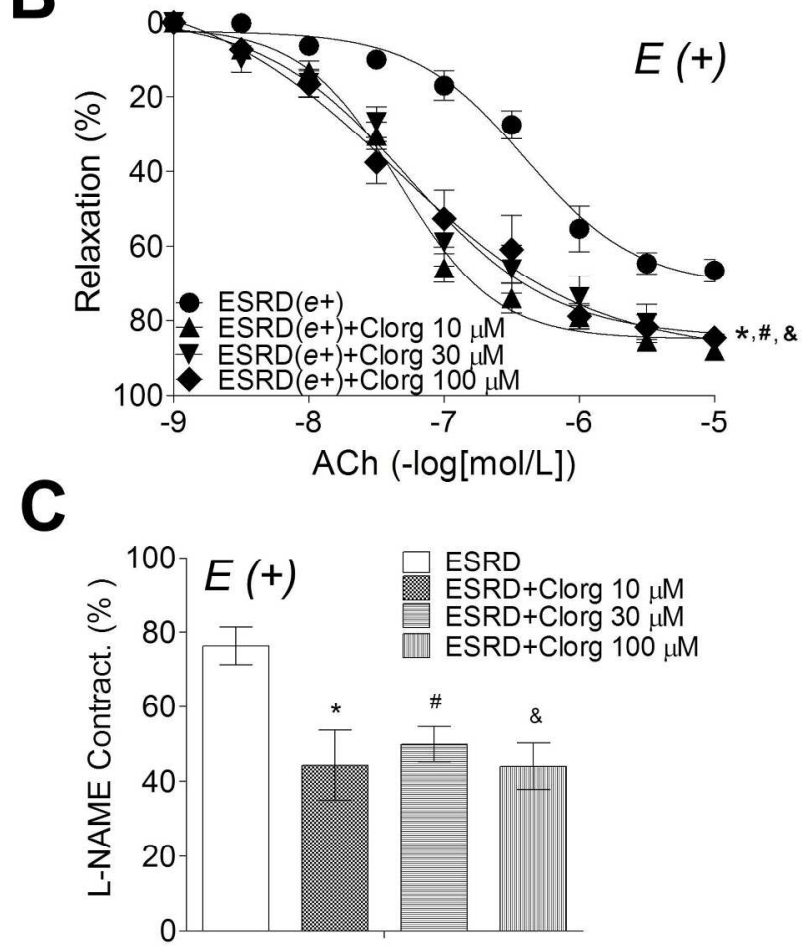

Figure 1. The effect of MAO-A inhibitor Clorgyline on vasomotor function in brachial artery collaterals with intact endothelium: (A) Phenylephrine induced contractions, (B) Acetylcholine-induced relaxation and (C) contraction to L-NAME $(10 \mu \mathrm{mol} / \mathrm{L})$ in brachial artery collaterals segments isolated from ESRD patients with indication of hemodialysis in the presence vs. absence of MAO-A inhibitor clorgyline (ESRD+Clorg, 10 $\mu \mathrm{mol} / \mathrm{L}, 30 \mu \mathrm{mol} / \mathrm{L}, 100 \mu \mathrm{mol} / \mathrm{L}) . \mathrm{n}=30, *, \#, \& \mathrm{p}<0.05 \mathrm{ESRD}$ with vs. without the named inhibitor.

$254 \times 338 \mathrm{~mm}(300 \times 300$ DPI $)$ 

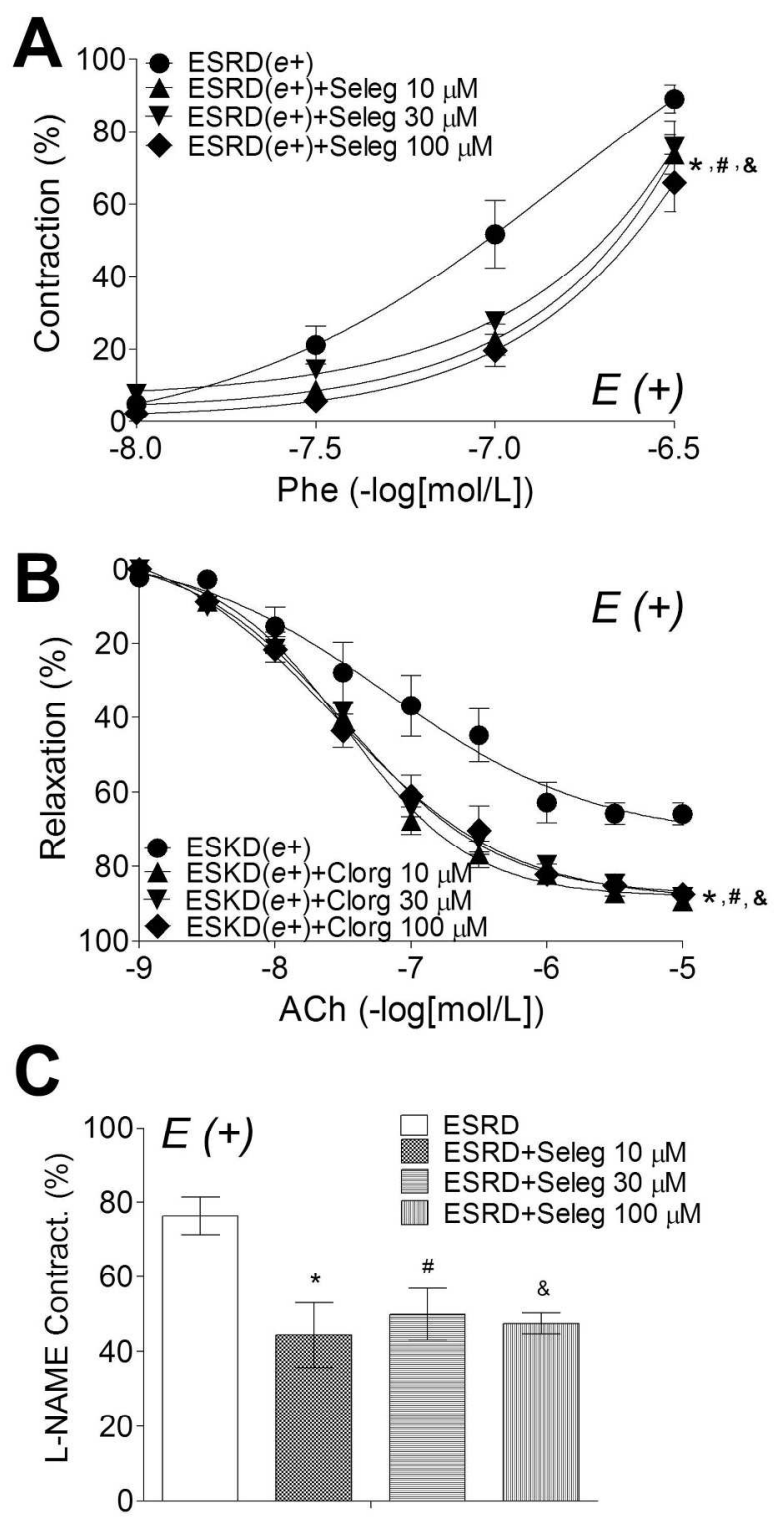

Figure 2. The effect of MAO-B inhibitor Selegiline on vasomotor function in brachial artery collaterals with intact endothelium: (A) Phenylephrine induced contractions, (B) Acetylcholine-induced relaxation and (C) contraction to L-NAME $(10 \mu \mathrm{mol} / \mathrm{L})$ in brachial artery collaterals segments isolated from ESRD patients with indication of hemodialysis in the presence vs. absence of MAO-B inhibitor selegiline (ESRD+Seleg, 10 $\mu \mathrm{mol} / \mathrm{L}, 30 \mu \mathrm{mol} / \mathrm{L}$,

$254 \times 338 \mathrm{~mm}(300 \times 300$ DPI $)$ 


\section{A}

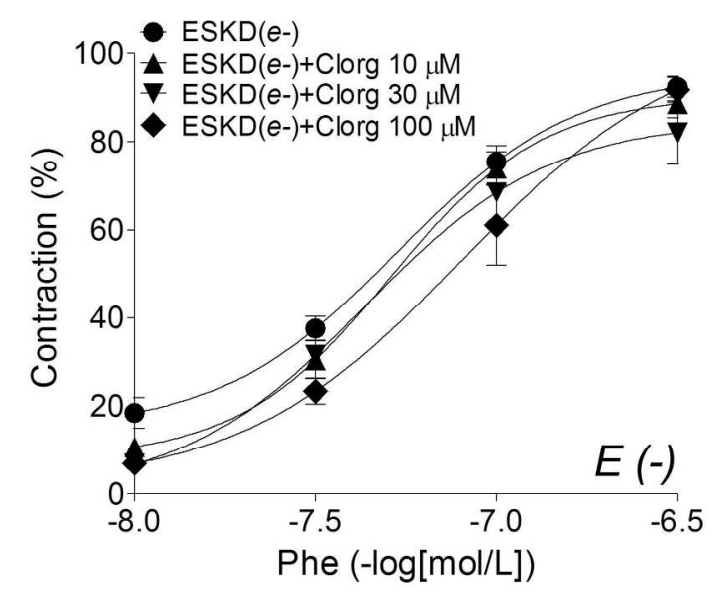

B

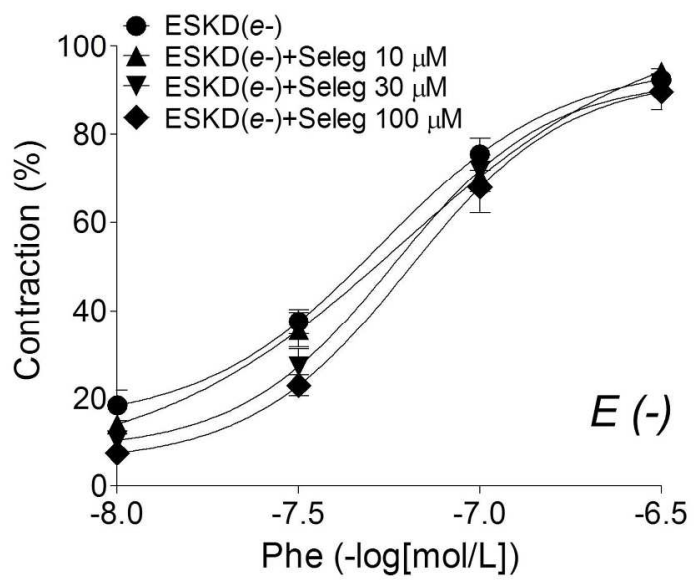

Figure 3. The effect of MAO inhibitors on vasomotor function in brachial artery collaterals with denuded endothelium: Phenylephrine induced contractions in brachial artery collaterals segments with denuded endothelium, isolated from ESRD patients with indication of hemodialysis in the presence vs. absence of (A)

MAO-A inhibitor clorgyline (ESRD+Clorg, $10 \mu \mathrm{mol} / \mathrm{L}, 30 \mu \mathrm{mol} / \mathrm{L}, 100 \mu \mathrm{mol} / \mathrm{L}$ ) and (B) MAO-B inhibitor selegiline (ESRD+Seleg, $10 \mu \mathrm{mol} / \mathrm{L}, 30 \mu \mathrm{mol} / \mathrm{L}, 100 \mu \mathrm{mol} / \mathrm{L}$ ), $\mathrm{n}=30, *, \#, \& \mathrm{p}<0.05 \mathrm{ESRD}$ with vs. without the named inhibitor.

$254 \times 338 \mathrm{~mm}(300 \times 300 \mathrm{DPI})$ 

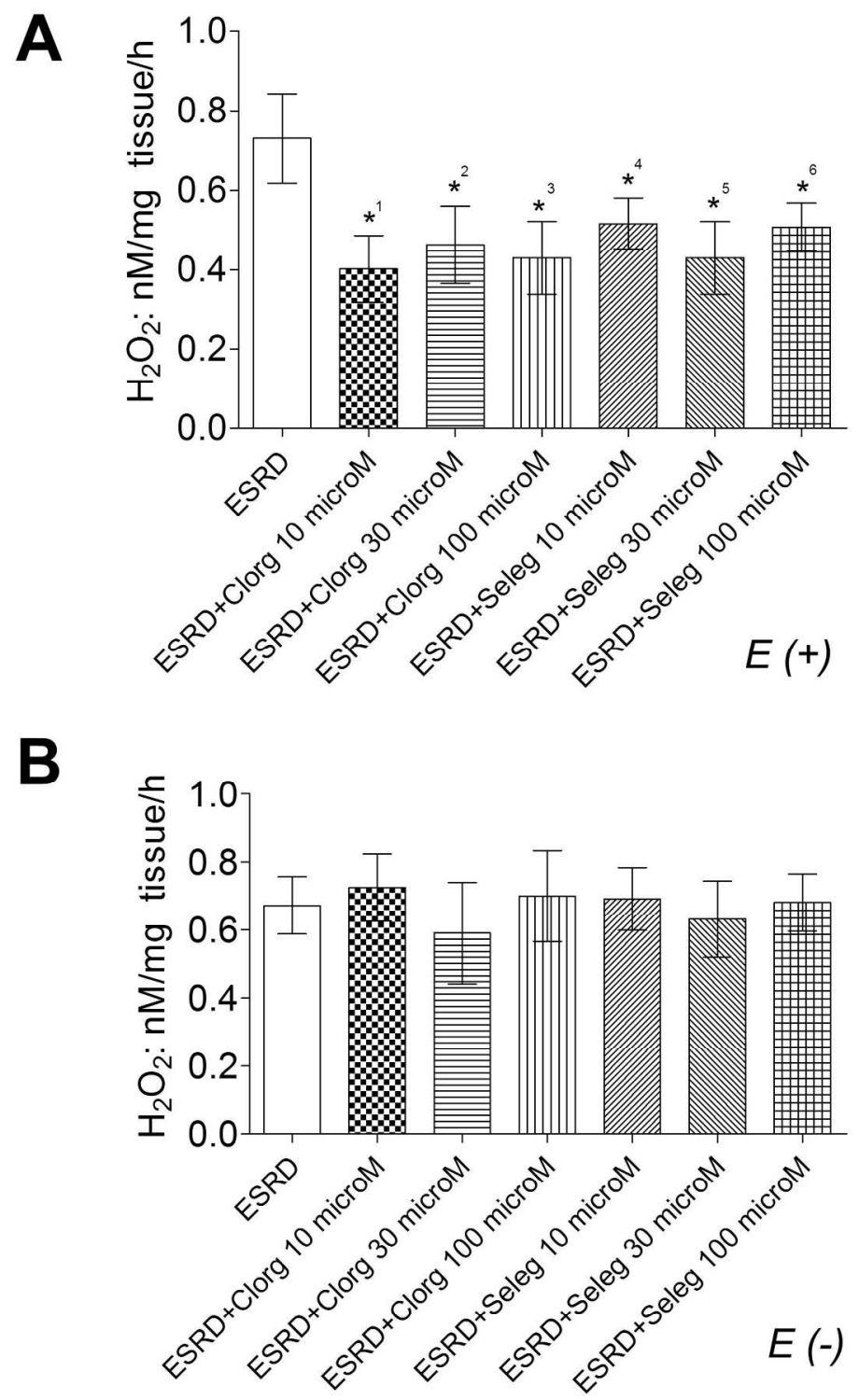

Figure 4. The effect of MAO inhibitors on ROS productionin brachial artery collaterals. (A) FOX Assay for $\mathrm{H} 2 \mathrm{O} 2$ measurements in brachial artery collaterals segments with endothelium and (B) denuded endothelium, isolated from ESRD patients with indication of hemodialysis in the presence vs. absence of MAO-A inhibitor clorgyline (ESRD+Clorg, $10 \mu \mathrm{mol} / \mathrm{L}, 30 \mu \mathrm{mol} / \mathrm{L}, 100 \mu \mathrm{mol} / \mathrm{L}$ ) and MAO-B inhibitor selegiline (ESRD+Seleg, $10 \mu \mathrm{mol} / \mathrm{L}, 30 \mu \mathrm{mol} / \mathrm{L}, 100 \mu \mathrm{mol} / \mathrm{L}) . \mathrm{n}=30, * 1-6 \mathrm{p}<0.05 \mathrm{ESRD}$ with vs. without the named inhibitor.

$254 \times 338 \mathrm{~mm}(300 \times 300$ DPI) 